\title{
Lethal acrodysgenital dwarfism: a severe lethal condition resembling Smith-Lemli-Opitz syndrome
}

\author{
M LE MERRER*, M L BRIARD*, S GIRARD + , N MULLIEZ , C MORAINE ${ }^{\circ}$ \\ AND M C IMBERT\|
}

From * Clinique et Unité de Recherches de Génétique Médicale INSERM U.12, Hôpital des Enfants Maladês.

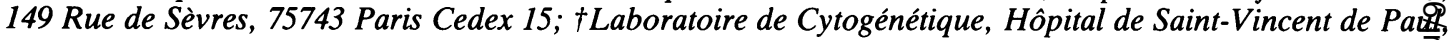
74 Avenue Denfert-Rochereau, 75674 Paris Cedex 14; $\neq$ Laboratoire d'Histologie et d'Immunologie, Hôpi胥l Saint-Antoine, 184 Rue du Faubourg Saint-Antoine, 75571 Paris Cedex 12; §Unité de Génétique, Centre Hospitalier Universitaire Bretonneau, 2 Boulevard Tonnelé, 37044 Tours Cedex; and ||Service Centră d'Anatomie et de Cytologie Pathologiques, Hôpital Antoine Béclère, 157 Rue de la Porte de Trivaux, 921 đad Clamart, France.

SUMMARY We report eight cases of a lethal association of failure to thrive, facial dysmorphisn ambiguous genitalia, syndactyly, pestaxial polydactyly, and internal developmental anomalie (Hirschsprung's disease, cardiac and renal malformation). This syndrome is likely to autosomal recessive and resembles Smith-Lemli-Opitz (SLO) syndrome. However, the lethality the common occurrence of polydactyly, and the sexual ambiguity distinguishes this conditiog from SLO syndrome. A review of published reports supports the separate classification of this syndrome for which we propose the name lethal acrodysgenital dwarfism.

In September 1985, at the meeting of the European Club of Genetic Counselling, we reported three cases of children with a syndrome reminiscent of the Smith-Lemli-Opitz syndrome. However, it seemed to us to differ from the latter because of the extent of the genital abnormality and the rapidly fatal evolution. ${ }^{1}$ Since then, we have encountered five new cases very similar to the first ones. Independently, Donnai et al ${ }^{2}$ have reported three similar cases. In this paper, we discuss our eight cases and compare them to other published cases. It appears that this syndrome constitutes a new entity which we propose to name lethal acrodysgenital dwarfism.

\section{Case reports}

Cases $1,2,3,4,6$, and 7 were encountered during genetic counselling sessions. Cases 5 and 8 were ascertained from anatomical and pathological records.

CASE 1

Case 1, a female, was the first child of young parents. She was born in the breech position in a state of fetal distress, weighing $2370 \mathrm{~g}$ and measur-

Received for publication 16 October 1986.

Revised version accepted for publication 7 January 1987 ing $44 \mathrm{~cm}$. The face was dysmorphic with a narrơ forehead, anteverted nares, broad and prominemt nasal bridge, angioma on the forehead, narrow and antimongoloid palpebral fissures, blepharoptos $\overrightarrow{\widehat{s}}$, and marked micrognathia. The head circumference was $31.5 \mathrm{~cm}$ and the neurological state very poor (ng 1).

In addition, there was bilateral clinodactyly of five fingers, proximally placed thumbs, and posfaxial polydactyly on the left hand. The feet alşo showed bilateral postaxial polydactyly, with sy?dactyly of the second and third toes. The fingers and toes were clenched. On examination, she was smal for her age with very widely spaced nipples, femate external genitalia, and a sacral dimple. No gonads were palpable.

$X$ ray examination showed a dense base to the skull, thin ribs, and narrow iliac bones. On the hand, the polydactyly affected the bones and the first metacarpal was short. On the right foot, the were only four metatarsals of which the last two were in the form of a $\mathrm{Y}$ thus giving rise to the polysyndactyly. On the left foot, the fourth and fifth metatarsals were joined proximally and the sixth toe had no bone (fig 2).

An examination of the eyes revealed bilater黑 congenital cataract. The karyotype was ma最 $(46, \mathrm{XY})$ and revealed the sexual ambiguity u迎 

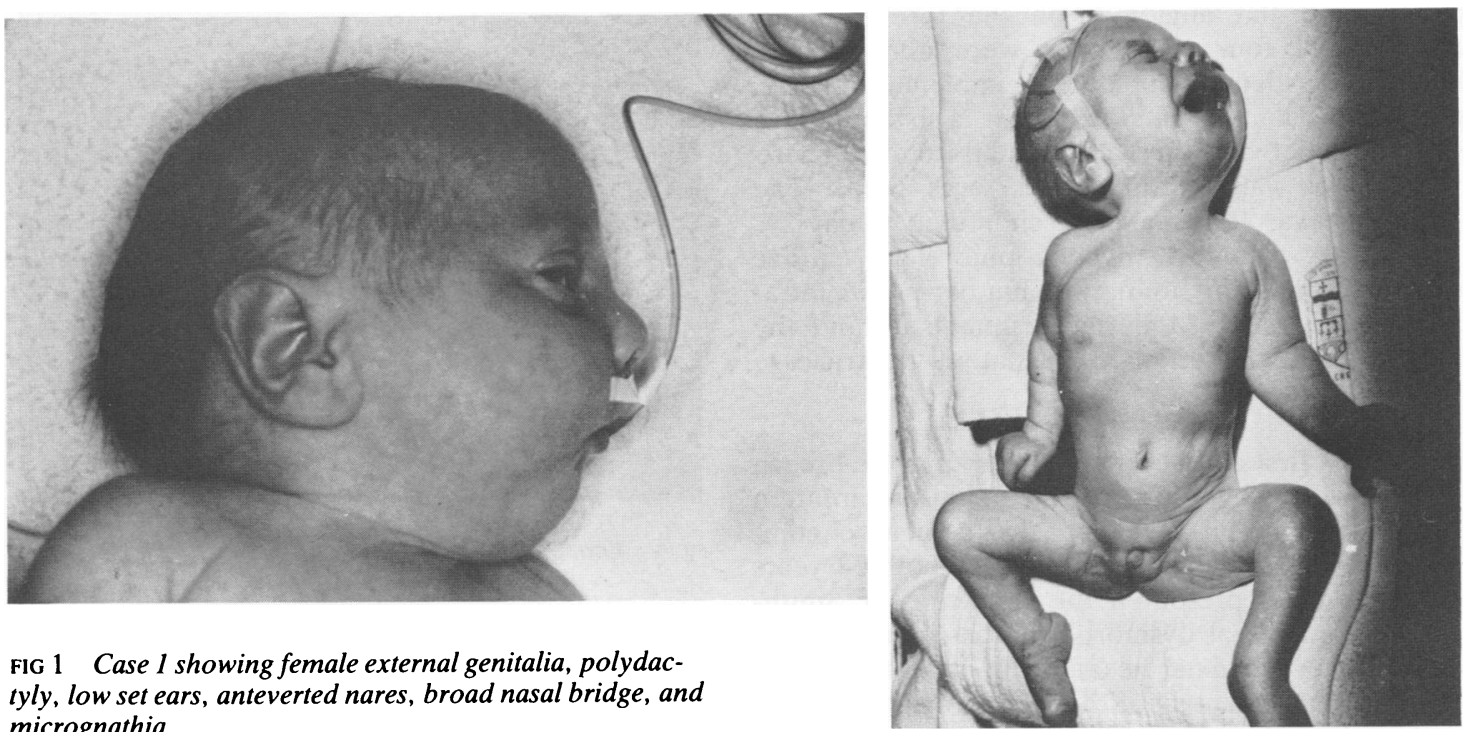

FIG 1 Case 1 showing female external genitalia, polydactyly, low set ears, anteverted nares, broad nasal bridge, and micrognathia.

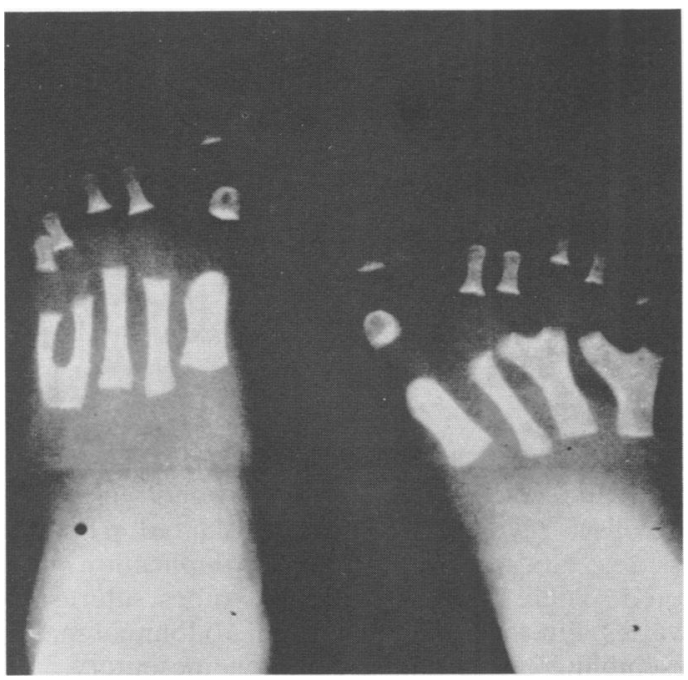

FIG 2 X ray of feet of case 1 .

suspected until then. The child died of pulmonary complications on day 45 .

Necropsy showed an ectopic left kidney, dilatation of the cavities of the right heart, and a macrophagic infiltration of the lungs. The uterus was absent but there were two male gonads and an epididymis. Histologically, the seminiferous tubules were immature and the interstitial cells were poorly developed.
CASE 2

The second child of a young couple was born after induced labour at 38 weeks. Ultrasound examination at 35 weeks showed retarded growth which was confirmed at birth (length $40.5 \mathrm{~cm}$, birth weight $2250 \mathrm{~g}$, head circumference $30 \mathrm{~cm}$ ).

There was marked dysmorphism including an antimongoloid slant of the palpebral fissures, marked micrognathia, and broad alveolar ridges. The tongue had a multicystic appearance and there was excessive skin on the back of the neck. Syndactyly of the second and third toes was noted as well as duplication of the fifth left toe. The child had club feet and dislocated hips. A sacral dimple was present. In the genital region, a voluminous mass was noted, as well as two large folds surrounding a vaginal cleft. No gonads could be palpated.

The child died shortly of respiratory distress. The karyotype was $46, \mathrm{XY}$.

Necropsy showed an atrial septal defect, a unilobar left lung, and a rudimentary uterus with two well formed fallopian tubes; the gonads had undergone male differentiation.

\section{CASE 3}

This child was of indeterminate sex, born at 35 weeks, in the incomplete breech position, birth weight $2180 \mathrm{~g}$, length $43 \mathrm{~cm}$, head circumference $30 \mathrm{~cm}$. The father and mother were 20 and 21 years old, respectively. The dysmorphism consisted of microcephaly with brachycephaly, poorly formed ears, a flattened nose with anteverted nares, cleft 
palate, and flat angiomas on the forehead and eyelids. All four extremities were abnormal: a bilateral vestigial sixth finger implanted in the proximal phalanx of the fifth finger, a sixth toe, and syndactyly between the second and third toes. There was talipes valgus and the cry was weak. The karyotype was 46,XY and the child died on day 24 .

Necropsy showed hypertrophic left cardiac cavities, small and immature lumbar-pelvic intraabdominal testes, Müllerian remnants behind the bladder, and dilatation of the lateral ventricles.

\section{CASE 4}

This was a first child born at 35 weeks in the breech position, with slight intrauterine growth retardation (length $46 \mathrm{~cm}$, birth weight $2800 \mathrm{~g}$, head circumference $33.5 \mathrm{~cm}$ ). The parents were both 34 years old. The child presented the characteristic SmithLemli-Opitz facial dysmorphism, associated with a cleft palate, postaxial hexadactyly of all four limbs (fig 3 ) with syndactyly of the second and third toes, and a bilateral simian crease. The external genitalia were very hypoplastic, but male (fig 5). The karyotype was $46, \mathrm{XY}$.

The child died on day 16 . Necropsy showed absence of internal male genital organs and the presence of a common mesentery and infiltration in the lungs.

\section{CASE 5}

The discovery of oligohydramnios and of major hypotrophy led to termination of pregnancy at 29

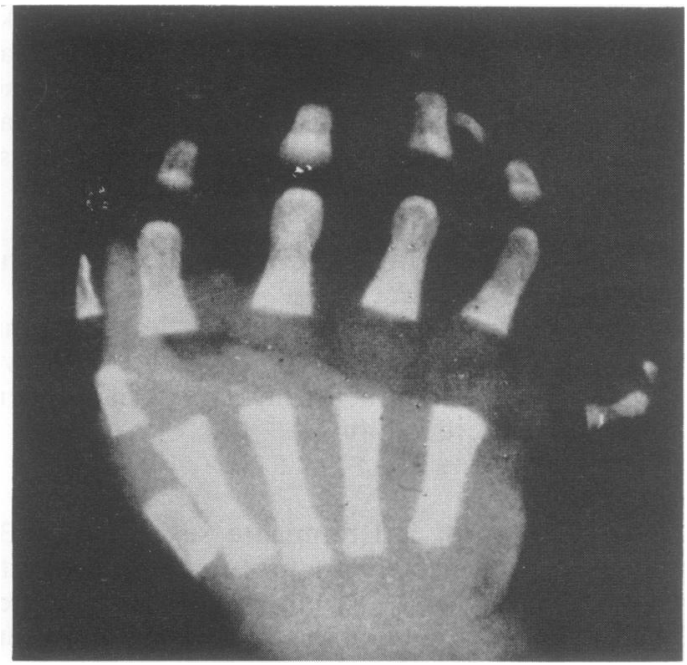

FIG $3 X$ ray of hand of case 4 showing postaxial polydactyly.

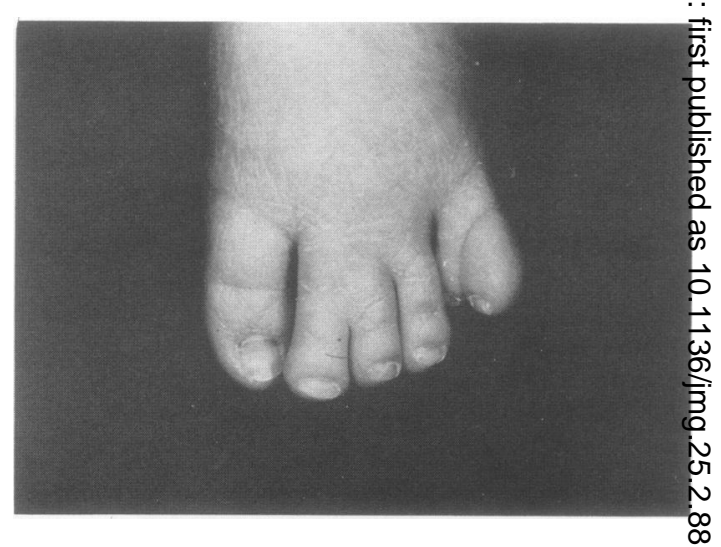

FIG 4 Foot of case 4 showing polysyndactyly of the toes.

FIG 5 Case 4 showing hypoplastic external genitalia.

weeks. The fetal karyotype was $46, \mathrm{XY}$. The exter nal genitalia were female with a blind vagina. A甲 necropsy, severe micrognathia, slanted palpebra角 fissures, and bilateral urethral duplication wer\& noted. There were no fallopian tubes, uterus, op ovaries, but there were two small abdominal masses. resembling testes and a common mesentery. N

CASE 6

This child was both small for dates and prematures (born at 30 weeks), birth weight $1850 \mathrm{~g}$, hea circumference $29.5 \mathrm{~cm}(<25$ th centile). She was born by caesarian section because of breect position and multiple malformations. She was phenotypically female and showed micrognathia, æ broad nasal bridge, anteverted nares, a high palate and horizontal palpebral fissures. The neck was short with an apparent excess of skin. The limbs seemed short with club feet, postaxial hexadactyl 


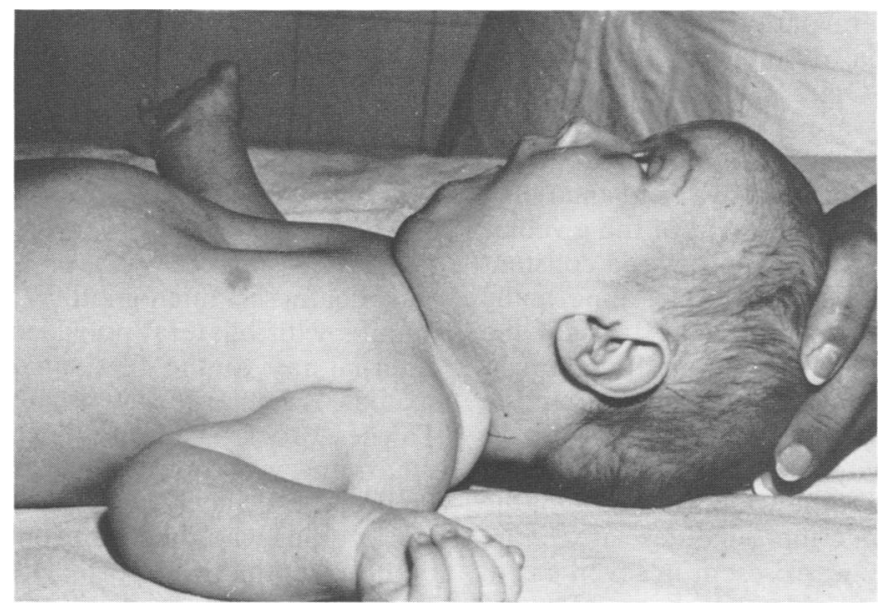

FIG 6 Case 7 showing micrognathia, polydactyly, excess of

loose skin on the neck, pectus excavatum, and low set ears.

of the left hand and foot, and syndactyly of the second and third toes. A sacral dimple was noted. Necropsy showed pulmonary hypoplasia and an interventricular septal defect. The gonads resembled testes but there was a very hypoplastic uterus. The right kidney was small and ectopic. The karyotype was $46, X Y$, inv(9).

\section{CASE 7}

This small for dates female child, born at term (birth weight $2480 \mathrm{~g}$ ), was admitted to hospital because of her dysmorphic appearance characterised by micrognathia, a flattened nasal bridge, an arched palate, low set and poorly formed ears, postaxial polydactyly of all four extremities, and hypertrophic labia majora. The neck was short with excess loose skin (fig 6). $X$ rays revealed a sixth lumbar vertebra (sacral dimple), confirmed the polydactyly (synostosis of the fifth metacarpal), and showed a short first metacarpal and brachymesophalangy of the sixth. The child died of heart failure with a patent ductus arteriosus. Necropsy showed large and lobular kidneys. The karyotype was $46, X X$.

\section{CASE 8}

This girl was born to a 17 year old mother of gypsy origin whose parents were consanguineous, but whose precise relationship was not known. As early as the 20th week, ultrasound suggested a low weight gain which was confirmed at birth (birth weight 2050 $\mathrm{g}$, head circumference $31 \mathrm{~cm}$, length $42 \mathrm{~cm}$ ). She presented with multiple congenital abnormalities and died after 16 days of life.

The karyotype was $46, \mathrm{XY}$. The face showed characteristic dysmorphology with cataracts and a cleft palate. Postaxial polydactyly was noticed on the hands and feet with a bilateral simian crease and syndactyly of the second and third toes. The external genitalia were female with hypertrophic labia majora and clitoris. The gonads could not be seen.

Necropsy revealed testes in the inguinal canals and a vagina devoid of Müllerian duct derivatives. There were no other anomalies of the internal organs with the exception of a retro-oesophageal subclavian artery and a patent ductus arteriosus. On examination of the skull, slight distension of the lateral ventricles and heterotopic cell clusters were observed. The pancreas appeared immature with large islets of Langerhans.

\section{Discussion}

The eight infants we have described obviously show the same pattern of malformations. The major element consists of the genital anomalies with an XY karyotype but complete failure of masculinisation of the external genitalia or even a true sex reversion. The testes were undescended, small, and appeared immature. The presence of a hypoplastic uterus or Müllerian remnants was noted in four out of the seven cases with a male karyotype.

In addition to these genital anomalies, facial 
dysmorphism and a general pattern of malformations was observed. The facial dysmorphism was reminiscent of Smith-Lemli-Opitz syndrome. The most characteristic features were the anteverted nostrils and micrognathia. In three cases out of eight, a cleft palate was associated with the above, and an arched palate was noted once. Enlargement of the alveolar ridges was noted in one case. There was a constant flattening of the nasal bridge, sometimes abnormally shaped ears, an excess of skin on the back of the neck (five cases out of six), and frontonasal angiomas.

However, the dysmorphic facial pattern found in our cases is not very specific as it does in fact consist of features found not only in the Smith-Lemli-Opitz syndrome, but also in other syndromes. On the other hand, the other abnormalities are more specific. Polysyndactyly was present in seven out of eight cases and was of variable expression, affecting at times a single hand, at other times all four limbs. Associated with this were other limb abnormalities, club feet or talipes valgus and short thumbs. The abnormalities of the genitalia, of the face, and of the extremities were accompanied by malformations of the internal organs. Renal hypoplasia was the most frequent and the heart may be affected (septal defect or patent ductus arteriosus). Cerebral abnormalities have also been noticed, such as ventricular dilatation as well as pulmonary abriormalities (lobulation abnormalities one case, pulmonary hypoplasia one case, pneumopathy three cases) (table 1).

The pattern of malformations described here is not in itself new. Without mentioning the earlier observations of Foerster and Casper, certain cases of the so called Ullrich-Feichtiger syndrome 'typu $\overrightarrow{\overrightarrow{5}}$ rostockiensis', such as those of Weber and Schwarz,,$\frac{3+}{\circ}$ seem quite similar to ours. Certainly, the Ullrich $\frac{\text { 음 }}{2}$ Feichtiger syndrome has proven to be extremelyen heterogeneous. ${ }^{4}$ In Feichtiger's initial observation (1943) the 'Würzburg' type is similar to trisomy 13 , or Meckel syndromes, whereas the 'Rostock' type, which is associated with preauricular appendages $\overrightarrow{0}$ and deafness, micrognathia, triphalangy of the thumbs with bilateral polydactyly of the hands, now external ray to the feet, anal atresia, and hypo spadias, is similar to what is currently designated theo Townes-Brock syndrome. ${ }^{5}$ The existence of thisis syndrome was questioned as early as 1975 by Pfeiffer and Slavaykoff. ${ }^{6}$ They described a sisterio and brother who died after only a few days of life both presenting with postaxial polydactyly, the boy? also having hypospadias. While considering the possibility of Ullrich-Feichtiger syndrome, these $e^{\mathbb{D}}$ authors concluded that it was more likely to be Smith-Lemli-Opitz syndrome. ${ }^{7}$ Other more recen⿷匚⿳丨コ丨 observations mention Smith-Lemli-Opitz syndromewith early lethality, in which the severely affected phenotype is accompanied by polydactyly. ${ }^{8-11}$ Based ${ }^{\circ}$ on their personal experience and other publisheo reports, Cherstvoy et al ${ }^{12}$ found a significant differs ence between the Smith-Lemli-Opitz cases that are associated with polydactyly and those that are not. ${ }^{10}$ The former seem to them to constitute a separate entity, characterised in particular by an earlie death, a higher frequency of renal anomalies, anc different cerebral malformations.

Coincidental with our first three observations? Donnai et al $^{13}$ published three cases in which the

TABLE 1 Features of lethal acrodysgenital dwarfism.

\begin{tabular}{|c|c|c|c|c|c|c|c|c|c|}
\hline & Case I & Case 2 & Case 3 & Case 4 & Case 5 & Case 6 & Case 7 & Case 8 & Total \\
\hline Chromosomes & 46.XY & $46, X Y$ & 46.XY & $46 . X Y$ & $46, X Y$ & $46 . X Y$ & $46 . \mathrm{XX}$ & $46, X Y$ & 7M. IF \\
\hline Phenotype & F & $\mathrm{F}$ & $\mathbf{F}$ & M (hypospadias) & $\mathbf{F}$ & $\mathbf{F}$ & $\mathbf{F}$ & $\mathbf{F}$ & \\
\hline Müllerian remnants & - & + & + & - & + & + & + & - & \\
\hline Immature testes & + & + & + & No testes & + & + & - & + & \\
\hline Weight (g) & 2370 & 2250 & 2180 & $280(x)$ & Terminated & 1850 & 2480 & 2050 & $8 / 8$ \\
\hline Dwarfism & + & + & + & + & + & + & + & + & $8 / 8$ \\
\hline Microcephaly & + & + & + & - & $?$ & + & + & + & $6 / 7$ \\
\hline Micrognathia & + & + & + & + & + & + & + & + & $8 / 8$ \\
\hline Anteverted nares & + & + & + & + & + & + & + & + & $8 / 8$ \\
\hline Low set ears & + & + & + & + & + & + & + & + & $8 / 8$ \\
\hline Cleft palate & - & - & + & + & - & + & - & + & $4 / 8$ \\
\hline Excess of skin on the neck & - & + & $?$ & + & $?$ & + & + & + & $5 / 6$ \\
\hline Postaxial polydactyly & + & + & + & + & ? & + & + & + & $7 / 7$ \\
\hline Simian crease & + & + & + & + & $?$ & + & + & + & $7 / 8$ \\
\hline Syndactyly of toes $2-3$ & + & + & + & + & + & + & + & + & $8 / 8$ \\
\hline Club foot (valgus) & - & + & + & - & $?$ & + & - & + & $4 / 6$ \\
\hline Sacral dimple & + & + & - & - & $?$ & + & + & - & $4 / 6$ \\
\hline Cataract & + & - & - & - & $?$ & $?$ & - & + & $2 / 7$ \\
\hline Urinary tract malformation & + & - & - & $?$ & + & + & + & - & $4 / 7$ \\
\hline Cardiac defect & + & + & + & $?$ & - & + & + & + & $6 / 8$ \\
\hline Pulmonary lobulation abnormality & + & + & $?$ & + & $?$ & - & - & - & $2 / 4$ \\
\hline
\end{tabular}


symptoins were comparable to those described here, and with which they associated other published cases. These authors differentiated these cases from the Smith-Lemli-Opitz syndrome as described in $1964 .^{7}$ Indeed, if delayed development and the characteristic facial dysmorphism are also present in the SLO syndrome, the most constant features are hypospadias or cryptorchidism or both in the male, without complete failure of masculinisation, and syndactyly between the second and third toes with or without club feet and metatarsus varus. Polydactyly is seen only exceptionally and early death only occurs in $20 \%$ of the cases.

In the light of our observations, the diagnosis of Smith-Lemli-Opitz syndrome in these unusual forms seems to us to deserve close scrutiny. This is confirmed by our analysis of 47 cases published under this title and analysed according to the criteria of lethality or presence of polydactyly.

Of these cases, 20 children out of 47 died in the first few months of life and their phenotype was different to that of survivors. Facial dysmorphology did not differ significantly between the two groups, but cleft palate was present in half the cases, and enlargement of the alveolar ridges was more frequent. On the other hand, postaxial polydactyly,

TABLE 2 Smith-Lemli-Opitz syndrome: two forms?

\begin{tabular}{|c|c|c|}
\hline & $\begin{array}{l}\text { 'Classic' } \\
(n=27)\end{array}$ & $\begin{array}{l}\text { 'Severe' } \\
(n=20)\end{array}$ \\
\hline Genitalia & 15 & 14 \\
\hline Ambiguous or female & - & 10 \\
\hline Cryptorchidism, hypospadias & 14 & 4 \\
\hline \multicolumn{3}{|l|}{ Extremities } \\
\hline Postaxial polydactyly & 3 & 14 \\
\hline Short thumb & 4 & 4 \\
\hline Syndactyly of toes & 25 & 19 \\
\hline \multicolumn{3}{|l|}{ Face } \\
\hline Microcephaly & 17 & $1517^{*}$ \\
\hline Micrognathia & 19 & 19 \\
\hline Cleft/high palate & 9 & 16 \\
\hline Anteverted nares & 18 & 15 \\
\hline Broad alveolar ridges or cyst & 3 & $9^{*}$ \\
\hline \multicolumn{3}{|l|}{ Malformation of internal organs } \\
\hline Cardiac defect & 4 & 15 \\
\hline Kidney anomalies & 4 & 10 \\
\hline 'Pneumopathy' & 3 & 8 \\
\hline Hirschsprung's disease & - & 8 \\
\hline
\end{tabular}

*Microcephaly and broad alveolar ridges were not quoted in all observations published. most frequently affecting all four limbs, and marked sexual ambiguity seemed to be characteristic of the lethal forms ( $73 \%$ against $11 \%$ and $71 \%$ against $0 \%$, respectively). Malformations of the internal organs were also more frequent, and were in themselves a measure of severity: cardiac malformations of all types, uni- or bilateral renal hypoplasia, and more particularly Hirschsprung's disease were present in eight out of the 20 fatal cases (table 2).

If we follow Cherstvoy et $a l^{34}$ and classify the 47 reviewed cases of Smith-Lemli-Opitz syndrome into two groups, 'with polydactyly' and 'without polydactyly', it appears quite clear that the sexual ambiguity is more severe when there is polydactyly and the prognosis then seems to be extremely poor (table 3).

This analysis indicates the need to differentiate the Smith-Lemli-Opitz syndrome from those cases with polydactyly, marked sexual ambiguity, and early death. The results of family studies contribute a further element to support this division. It has been established that the pattern of inheritance of the Smith-Lemli-Opitz syndrome is autosomal recessive, and this is confirmed by the consanguinity found in certain families and the existence of multiple affected sibs. Within families, the degree of severity is very similar, as one would expect according to genetic heterogeneity. A possible exception is family 1 reported by Dallaire, ${ }^{16}$ in which two seriously affected children had severe polydactyly, the third child having no polydactyly. In this family, described in 1969 , the author mentions an abnormally long chromosome 16 in the mother that was also present in some of the normal children as well as in some of the affected ones. Without sufficiently precise karyotype studies (marker studies) there remains doubt about the validity of the diagnosis.

\section{A NEW PATTERN OF MALFORMATIONS}

We can therefore distinguish the Smith-LemliOpitz syndrome from the new pattern of malformations reported here, which is also transmitted in an autosomal recessive fashion, and which we propose to name lethal acrodysgenital dwarfism.

Apart from our eight observations and the three reported cases of Donnai et al, ${ }^{13}$ and very recently the case of Scarbrough et al, ${ }^{28}$ we can include in this

TABLE 3 Smith-Lemli-Opitz syndrome: heterogeneity.

\begin{tabular}{|c|c|c|c|c|}
\hline$N=47$ & Sexual ambiguity & Early death & $\begin{array}{l}\text { Pulmonary } \\
\text { abnormality }\end{array}$ & $\begin{array}{l}\text { Malformation of } \\
\text { internal organs }\end{array}$ \\
\hline With polydactyly $(\mathrm{n}=17)^{3}+\mathrm{k}-111+1 \mathrm{x}$ & 83 & 70 & 70 & 75 \\
\hline Without polydactyly $(n=20)^{2} 15 \quad 16 \quad 14-27$ & 10 & 25 & 10 & 50 \\
\hline
\end{tabular}


entity the cases of Kohler, ${ }^{11}$ Kretzer et al, ${ }^{10}$ cases 1 and 4 of Cruveiller et al, ${ }^{15}$ Lipson and Hayes, ${ }^{17} \mathrm{Akl}$ et al, ${ }^{14} \mathrm{Kim}$ and Bootwell, ${ }^{22}$ Zizka et al, ${ }^{9}$ Greene et $a l,{ }^{8}$ Lowry, ${ }^{29}$ and Pfeiffer and Slavaykoff. ${ }^{6}$ The cases of Cherstvoy $e t a^{12}$ and of Pinsky and DiGeorge $^{26}$ are closer to the classical Smith-LemliOpitz syndrome. If the lack of karyotype makes us doubt the earlier observation of Weber and Schwarz ${ }^{3}$, we think we can retain the case of Patterson $e t a l^{25}$ in spite of the lack of polydactyly; the phenotype is female whereas the karyotype is $46, X Y$, the severe dysmorphology is comparable, there is excessive skin around the neck, flexion contractures of the fingers, elbows, knees and hips, and Hirschsprung's disease. This last point deserves comment. Intestinal ganglionosis, responsible for Hirschsprung's disease and found in eight cases, is a very unusual finding in syndromes of multiple congenital abnormalities and appears to be very specific. The same is true for the persistence of Müllerian remnants ${ }^{11} 1325$ (our cases 2, 3, and 6). Finally, a number of other anomalies can be mentioned including cysts of the mouth and tongue, particular histological lesions of the pancreas, and cataracts ${ }^{1013}$ (our cases 1 and 8 ).

\section{THE DIFFERENTIAL DIAGNOSIS}

We question the 'new lethal syndrome' of Rutledge et $a l^{30}$ described by Donnai et al. ${ }^{13}$ If most of the abnormalities are compatible with the pattern of malformations that we describe, others are not: agenesis of the biliary vesicle, microglossia, and findings from bone $x$ rays determine a slightly different pattern of malformations. The authors recognise that if certain signs were also found in Kohler's case, others, such as severe mesomelic dwarfism, distinguish it totally.

Similarly, the C syndrome, ${ }^{31}$ Hall-Pallister syndrome, ${ }^{32}$ and the hydrolethalus syndrome are easily eliminated, since the acrodysgenital dwarfism syndrome described here lacks the signs specific to each of them, namely trigonocephaly for the $\mathrm{C}$ syndrome, hamartomas for the Hall-Pallister syndrome, and hydramnios and hydrocephalus for the hydrolethalus syndrome. In the same way, the absence of kidney and liver cysts excludes the diagnosis of Meckel's syndrome. However, in a commentary on the variability of the Smith-LemliOpitz syndrome, Lowry et al ${ }^{8}$ questioned whether in similar cases these features could not result from Meckel's syndrome. This seemed to him to be possible in view of the absence of renal lesions, or alternatively they could be a variant of the SmithLemli-Opitz syndrome. The lethal acrodysgenital dwarfism syndrome is an answer to their question.
Trisomy 13 is the only other possible differential diagnosis and in this case simple karyotype analysis? must be performed systematically to exclude this.

\section{GENETIC COUNSELLING}

The familial observations concerning two sibs, ${ }^{6} 1 \frac{1}{\Omega}$ and the parental consanguinity found in the case of $\mathrm{Akl}$ et al ${ }^{14}$ and our case 8, are arguments in favour of an autosomal recessive pattern of inheritance and indicate that caution is required in genetic counsel $-\vec{\omega}$ ling. Prenatal diagnosis would entail a decision on the chromosomal sex (fetal karyotype) and the appearance of the fetus on prenatal ultrasono graphy.

\section{Conclusion}

In spite of the resemblances and of the difficulties in classifying certain cases in one category or the other ${ }_{\infty}^{T}$ we feel justified in proposing a new syndrome, lethar acrodysgenital dwarfism, which is different from then Smith-Lemli-Opitz syndrome, with the reservations imposed by the lack of information concerning theo mutations responsible, which may or may not bees allelic.

We would like to thank J Canet, Centre Hôspitalier Intercommunal de Créteil, and $\mathbf{M}$ Tournaire, Hôpi-ẵ tal Saint-Vincent de Paul de Paris, for their data. We are grateful to Professor $J$ Frézal and $D r P_{\vec{R}}$ Maroteaux for their help. We also thank Gisèle Ga亭 for secretarial assistance.

\section{Addendum}

After this paper had been submitted for publication a report appeared in the American Journal of Medical Genetics in which Cynthia Curry described. 19 children with a syndrome called Smith-LemliOpitz type II. All the features described in the above report provide further evidence of the existence of a discrete phenotype, more severe than Smith-Lemli-Opitz syndrome and to be distinguished? from it. Curry's observations are fully consistent with those described in our paper. For all these reasons it could be misleading to lump this entity together with the original SLO syndrome. Al N though, as outlined in the American Journal of Medical Genetics editorial comment, the possibilityo of allelic mutation cannot be excluded, it seems better, at least on clinical grounds, to distinguishe two syndromes. Accordingly, and bearing in mindo the main differential features in our cases, as well aso in those of Curry and Donnai et al, we propose to

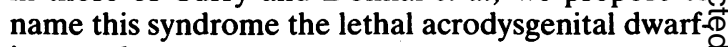
ism syndrome. 


\section{References}

${ }^{1}$ Le Merrer M, Briard ML, Chauvet ML. Une étiologie méconnue de l'ambiguité sexuelle: syndrome de Smith-Lemli-Opitz ou entité nouvelle? J Genet Hum 1987;35:187-93.

2 Deaton JG, Austin T, Mendoza LO, Tex M. Smith Lemli Opitz syndrome in a 23-year-old man. Arch Intern Med 1973;132: 422-3.

${ }^{3}$ Weber VJW, Schwarz H. Der typus rostockiensis UllrichFeichtiger. Dyskranio-pygo-phalangie. Helv Paediatr Acta 1960; 2:163-70.

${ }^{4}$ Ullrich-Bonn O. Der statut bonnevie-Ullrich im rahmen anderer 'dyscranio-dysphalangien'. In: Assmann H, Schittenhelm A, Schoen R, Glanzmann E, De Rudder B, eds. Ergebnisse der Inneren Medizin und Kinderheilkunde. Berlin: Springer-Verlag, 1951:456-8.

5 Townes PL, Brocks ER. Hereditary syndrome of imperforate anus with hand, foot, and ear anomalies. J Pediatr 1972;81: 321-6.

${ }^{6}$ Pfeiffer RA, Slavaykoff $\mathrm{H}$. Gibt es ein syndrome nach Ullrich und Feichtiger? Klin Paediatr 1975;187:176-80.

7 Smith DW, Lemli L, Opitz JM. A newly recognized syndrome of multiple congenital anomalies. J Pediatr 1964;64:210-7.

${ }^{8}$ Greene C. Pitts W, Rosenfeld R, Luzzatti L. Smith Lemli Opitz syndrome in two $46, \mathrm{XY}$ infants with female external genitalia. Clin Genet 1984;25:366-72.

9 Zizka J, Maresova J, Kerekes Z, Nozicka Z, Juttnerova V, Balicek P. Case report: intestinal aganglionosis in the Smith Lemli Opitz syndrome. Acta Paediatr Scand 1983;72:141-3.

${ }^{10}$ Kretzer FL, Hittner HM, Mehta RS. Ocular manifestations of the Smith Lemli Opitz syndrome. Arch Ophthalmol 1981;99: 2000-6.

"Kohler HG. Brief clinical report: familial neonatally lethal syndrome of hypoplastic left heart, absent pulmonary lobation, polydactyly, and talipes, probably Smith Lemli Opitz (RSH) syndrome. Am J Med 1983;14:423-8.

12 Cherstvoy ED, Lazjuk GI, Ostrovskaya TI, et al. The Smith Lemli Opitz syndrome: a detailed pathological study as a clue to aetiological heterogeneity. Virchows Arch (Pathol Anat) 1984; 404:413-25.

13 Donnai D, Young ID, Owen WG, Clark SA, Miller PFW, Knox WF. The lethal multiple congenital anomaly syndrome of polydactyly, sex reversal, renal hypoplasia, and unilobular lungs. J Med Genet 1986;23:64-71.

14 Akl KF, Khudr GS, Der Kaloustian VM, Najjar SS. The Smith Lemli Opitz syndrome: report of a consanguineous Arab infant with bilateral focal renal dysplasia. Clin Pediatr 1977;16:665-8.

15 Cruveiller JM, Sika S, Lafourcade J. Nanisme de Smith Lemli Opitz: a propos de quatre observations. Revue de la littérature. Ann Pediatr 1977;24:843-51.

16 Dallaire L. Syndrome of retardation with urogenital and skeletal anomalies (Smith Lemli Opitz syndrome): clinical features and mode of inheritance. J Med Genet 1969;6:113-20.

17 Lipson A, Hayes A. Smith Lemli Opitz syndrome and Hirschsprung disease. J Pediatr 1984;104:177.

${ }^{18}$ Lowry RB, Miller JF, MacLean JR. Micrognathia, polydactyly, and cleft palate. $J$ Pediatr 1968;72:859-61.
19 Blair RH, Martin JK. A syndrome characterised by mental retardation, short stature, craniofacial dysplasia, and genital anomalies occurring in siblings. $J$ Pediatr 1966;69:457-9.

${ }^{20}$ Finley SC, Finley WH, Monsky DB. Cataracts in a girl with features of the Smith Lemli Opitz syndrome. J Pediatr 1969;75: 706-7.

21 Johnson VP. Smith Lemli Opitz syndrome: review and report of two affected siblings. $Z$ Kinderheilkd 1975;119:221-34.

22 Kim EH, Boutwell WC. Smith Lemli Opitz syndrome associated with Hirschsprung disease, 46,XY female karyotype, and total anomalous pulmonary venous drainage. J Pediatr 1985;106: 860-1.

${ }^{23}$ Lowry RB, Yong SL. Borderline normal intelligence in the Smith Lemli Opitz (RSH) syndrome. Am J Med Genet 1980;5: 137-43.

${ }^{24}$ Park SC, Needles CF, Dimich I, Sussman L. Congenital heart disease in an infant with the Smith Lemli Opitz syndrome. $J$ Pediatr 1968:73:425-7.

25 Patterson K, Toomey KE, Chandra RS. Hirschsprung disease in a 46,XY phenotypic infant girl with Smith Lemli Opitz syndrome. J Pediatr 1983;103:425-7.

${ }^{26}$ Pinsky L, DiGeorge AM. A familial syndrome of facial and skeletal anomalies associated with genital abnormality in the male and normal genitals in the female: another cause of male pseudohermaphroditism. J Pediatr 1965;66:1049-54.

${ }^{27}$ Ruvalcaba RHA, Reichert A, Smith DW. Smith Lemli Opitz syndrome: case report. Arch Dis Child 1968;43:620-3.

${ }^{28}$ Scarbrough PR. Huddleston K. Finley SC. An additional case of Smith Lemli Opitz syndrome in a 46,XY infant with female external genitalia. J Med Genet 1986;23:174-5.

${ }^{29}$ Lowry RB. Editorial comment: variability in the Smith Lemli Opitz syndrome: overlap with the Meckel syndrome. Am J Med Genet 1983:14:429-33.

30) Rutledge JC, Friedman JM, Harrod MJE, et al. A "new" lethal multiple congenital anomaly syndrome: joint contractures, cerebellar hypoplasia, renal hypoplasia, urogenital anomalies, tongue cysts, shortness of limbs, eye abnormalities, defects of the heart, gallbladder agenesis, and ear malformations. Am J Med Genet 1984;19:255-64.

31 Opitz JM, Johnson RC, McCreadie SR. The C-syndrome of multiple congenital anomalies. Birth Defects 1969;5:161-6.

${ }^{32}$ Hall JG, Pallister PD, Clarren SK, et al. Congenital hypothalamic hamartoblastoma, hypopituitarism, imperforate anus and post-axial polydactyly-a new syndrome? Am J Med Genet 1980;7:47-74.

${ }^{33}$ Salomen R, Herva R, Reijo M. The hydrolethalus syndrome: delineation of a 'new' lethal malformation syndrome based on 28 patients. Clin Genet 1981;19:321-30.

${ }^{34}$ Cherstvoy ED, Lazjuk GI, Lurie LW, Nedzved MK, Usoev SS. The pathological anatomy of the Smith Lemli Opitz syndrome. Clin Genet 1975;7:382-7.

Correspondence and requests for reprints to Dr $M$ Le Merrer, Clinique de Génétique Médicale, INSERM U.12, Hôpital des Enfants Malades, 149 Rue de Sèvres, 75743 Paris Cedex 15, France. 